\title{
Implementasi Prinsip Usability F-Shape Pattern \\ Pada Konten Website
}

\author{
Jimmy Hendisaro Zebua ${ }^{1}$ \\ 22074293@students.ukdw.ac.id
}

\author{
Restyandito ${ }^{2}$ \\ dito@ti.ukdw.ac.id
}

\author{
Lucia D. Krisnawati ${ }^{3}$ \\ anton@ti.ukdw.ac.id
}

\begin{abstract}
Website as a medium of information can not be separated from website content itself. How visitors get the information they want is very dependent on the placement of such information. This research which involve the design and testing of respondents concluded that in general, users tend to read using $n$ " $F$ " pattern, therefore the lay out of the most important content must be placed on both the recommended reading area of the " $F$ " pattern. This research is using the Informatics Engineering's website as case study and propose a better design to improve the readibility of the information based on " $F$ " pattern.
\end{abstract}

Kata Kunci : Website, F-Pattern, Konten Website, Usability

\section{PENDAHULUAN}

Website mempunyai tujuan yang salah satunya sebagai media informasi yang diperuntukkan bagi siapa saja dan dapat diakses darimana saja. Maka sudah sepantasnya sesuatu yang ditujukan untuk untuk dilihat dan dinikmati pengguna, perlu dibuat dengan memperhatikan kapabilitas dan faktor kenyamanan user atau pengguna juga.

Untuk itu perlu adanya suatu desain website yang memperhatikan kapabilitas pengguna terutama dalam hal memperoleh informasi yang tersedia di website. Untuk mengetahui bagaimana pendapat user, hal apa yang mempengaruhi atensi (warna, gambar, dll), kebiasaan user ketika ber-internet, serta rekomendasi, maka diperlukan adanya pengumpulan data (dalam penelitian ini menggunakan kuisoner), serta pengujian yang bisa menentukan titik atensi pada desain. sementara untuk cara membaca user digunakan teori FPattern (pola pergerakan mata ketika membaca) sebagai teori utama yang merupakan salah satu hasil dari proses eyetracking.

\footnotetext{
${ }^{1}$ Teknik Informatika, Fakultas Teknologi Informasi, Universitas Kristen Duta Wacana, Yogyakarta

${ }^{2}$ Teknik Informatika, Fakultas Teknologi Informasi, Universitas Kristen Duta Wacana, Yogyakarta

${ }^{3}$ Teknik Informatika, Fakultas Teknologi Informasi, Universitas Kristen Duta Wacana, Yogyakarta
} 


\section{HORIZONTAL ATTENTION PATTERN}

Jacob Nielsen dalam artikelnya pada 6 april 2010 menyatakan :

“distribusi waktu ketika proses membaca(melihat halaman web) lebih banyak pada area sebelah kiri layar".

Hasil dari penelitiannya tersebut menyimpulkan bahwa perhatian user 2 kali lebih besar pada area sebelah kiri layar daripada di area sebelah kanan, atau jika dihitung persentasenya maka :

- Bagian kiri layar : 69\% dari total waktu memperhatikan

- Bagian kanan layar : 30\% dari total waktu user memperhatikan

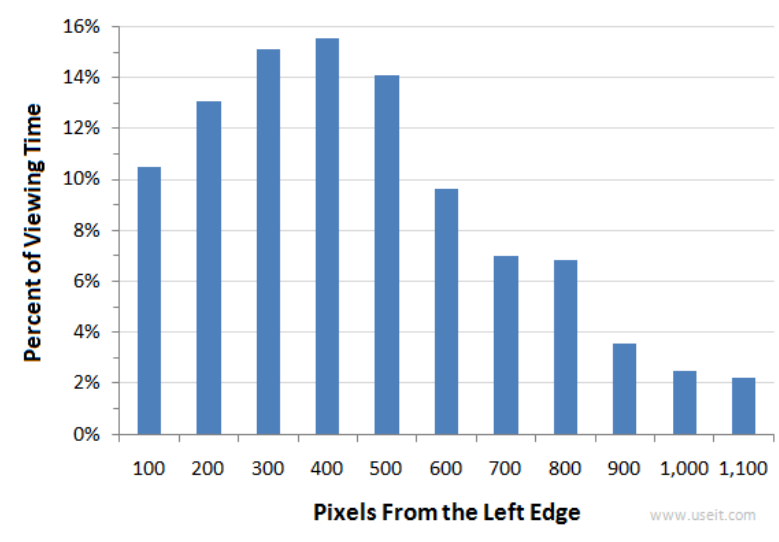

Gambar 1. Tingkat atensi dimulai dari sebelah kiri

\section{EYE MOVEMENT DAN F-PATTERN}

Dalam hipotesis minds-eyenya, Nielsen (2010, hal. 10) juga menyatakan bahwa halaman web terlalu luas bagi user untuk diperhatikan, dan web yang mampu membuat user fokus terhadap apa yang dia cari (tidak overlooking dan menghabiskan waktu terhadap hal yg tidak penting) adalah web yang dikunjungi dan dikunjungi lagi oleh $u s e r$.

Jacob Nielsen dalam artikelnya pada 17 april 2006 menyatakan :

"Visualisasi eyetracking menunjukkan bahwa user lebih sering membaca dalam polabaca berbentuk $F$ : dua garis datar horizonta diikuti dengan garis vertikal ".

Hasil dari eyetracking dan heatmaps (yang menyorot frekuensi dan lokasi pandangan mata), menunjukkan bahwa mata manusia bergerak sangat cepat dengan pola tertentu ketika men-scan konten website yang berupa tulisan. Penelitian selanjutnya merekam bagaimana 232 user mengamati ribuan website, dan disimpulkan bahwa users punya pola membaca umum yang konsisten sekalipun ketika mengamati website yang berbeda. Pola membaca ini terlihat seperti bentuk F dan terdiri dari 3 komponen : User 
pertama kali membaca dalam pola pergerakan horizontal dan biasanya melewati area atas halaman, kemudian user mengamati ke bagian bawah (dibawah pola horizontal pertama) dan membaca pada area horizontal kedua yang lebih pendek dibanding yang pertama.

Dan terakhir, user men-scan konten disebelah kiri dengan pola vertical, dengan kecepatan yang lebih lambat dibanding dua proses sebelumnya. Terkadang proses scan yang dilakukan tidak persis sama dengan 3 tahapan ini, sehingga pola membaca terlihat seperti $\mathrm{E}$ ketimbang F, atau L terbalik (garis horizontal di atas)

Georg Buscher dalam artikelnya pada 4 april 2009 menyatakan :

"salience dipengaruhi oleh kontras, warna, intensitas, kepadatan, dan orientasi. Fixation pertama terletak pada area paling menarik, dan fixation selanjutnya terletak pada area informasi tambahan yang berhubungan dengan apa yang menarik bagi user. Salience berpengaruh pada fixation pertama sedangkan fixation kedua dan seterusnya lebih dipengaruhi oleh memory dan ekpektasi user".

\section{METODE PENELITIAN}

Penelitian yang dilakukan menggunakan beberapa pendekatan metode. Dimulai dengan benchmarking beberapa situs sejenis untuk memperoleh informasi mengenai desain yang baik dilanjutkan dengan penyebaran kuisoner yang ditujukan untuk memperoleh data berupa, demografi partisipan, hal-hal yang menarik atensi, rekomendasi desain dan konten,respon positif dan negative terhadap desain. Dari Hasil Kuisoner, pada saat pertama kali melihat website (pengujian terhadap 4 website pembanding), atensi/ perhatian pertama sebagian besar tertuju pada area atas (Menu, Banner, Logo) dan kiri sebelum scrolling (Menu, Link). Sementara yang tertuju langsung ke area tengah (teks seperti berita, event) sangat sedikit, seperti tampak pada gambar 2.

Dari hasil benchmarking dan kuesioner tersebut dirancanglah desain situs yang baru. Desain tersebut diujikan menggunakan analisis pola "F" berdasarkan hasil heatmap, jika hasil yang diperoleh belum baik maka dilakukan desain ulang hingga diperoleh desain akhir dnegan titik atensi yang sesuai dengan pola "F". Untuk menguji desain yang diperoleh, maka dilakukan pengujian terakhir pada pengguna dengan menggunakan metode task dan skenario.

Subjek penelitian berjumlah 15 orang pengguna aktif internet di UKDW, yang terdiri dari mahasiswa dan dosen. Data yang diperoleh kemudian dianalisa dan digunakan sebagai acuan dalam pembuatan desain situs yang baru. Sementara untuk tahap pengujian, partisipan yang terlibat berjumlah 7 orang, dimana mereka diminta untuk melakukan beberapa task sederhana. 


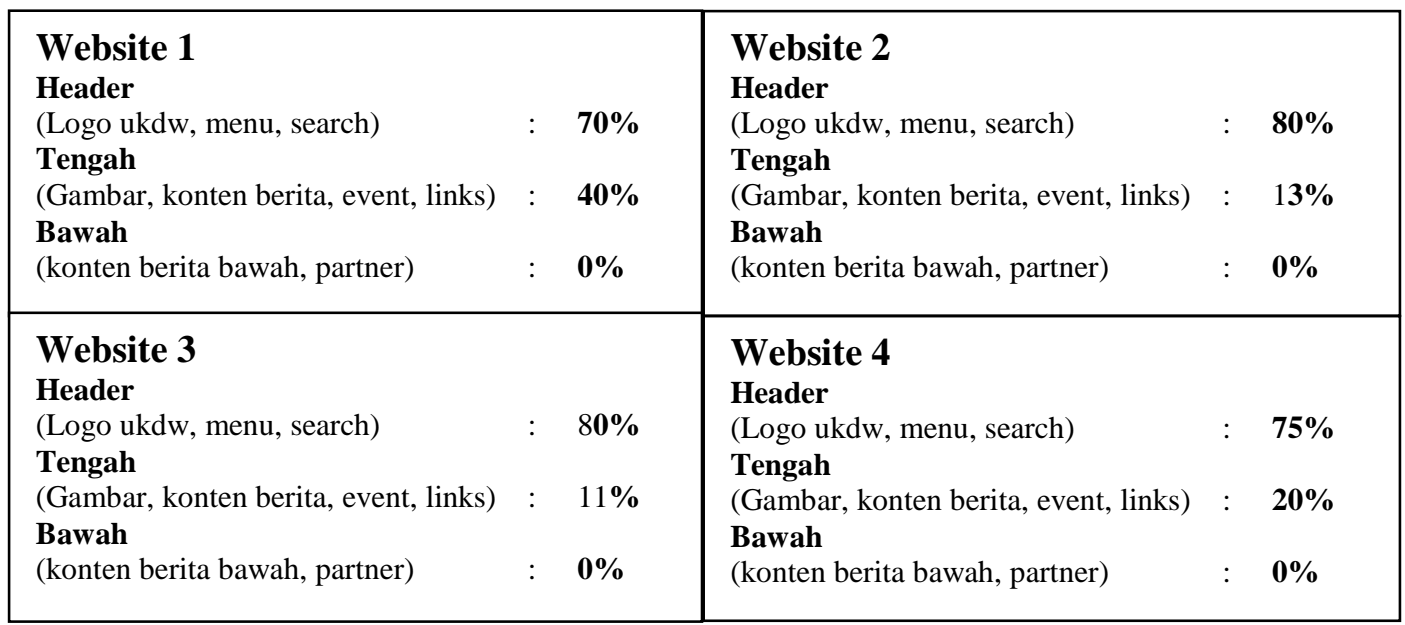

Gambar 2. Rekomendasi berdasarkan kuisoner hasil benchmarking.

\section{PENGUJIAN DESAIN}

Untuk mengetahui sebaran atensi dan pola scanning user ketika melakukan scanning, penelitian menggunakan layanan Feng-GUI (www.feng-gui.com) . yang mana dalam proses pengujiannya menggunakan teknologi dan teori IMK seperti neuro-science studies of Natural Vision Processing, Computational Attention, eye-tracking sessions, perception and cognition of human atau dengan kata lain "What people are looking at?".

Dari hasil perhitungan, delay terbesar pada pengukuran ini adalah delay pada area DWTC yang mencapai $77.43 \mathrm{~ms}$. Sesuai dengan rekomendasi cisco delay dengan range terbaik adalah delay antara 0-150 ms, dengan demikian delay terbesar yang terjadi pada jaringan Intranet UKDW masih tergolong dalam golongan delay terbaik yaitu di antara 0$150 \mathrm{~ms}$.

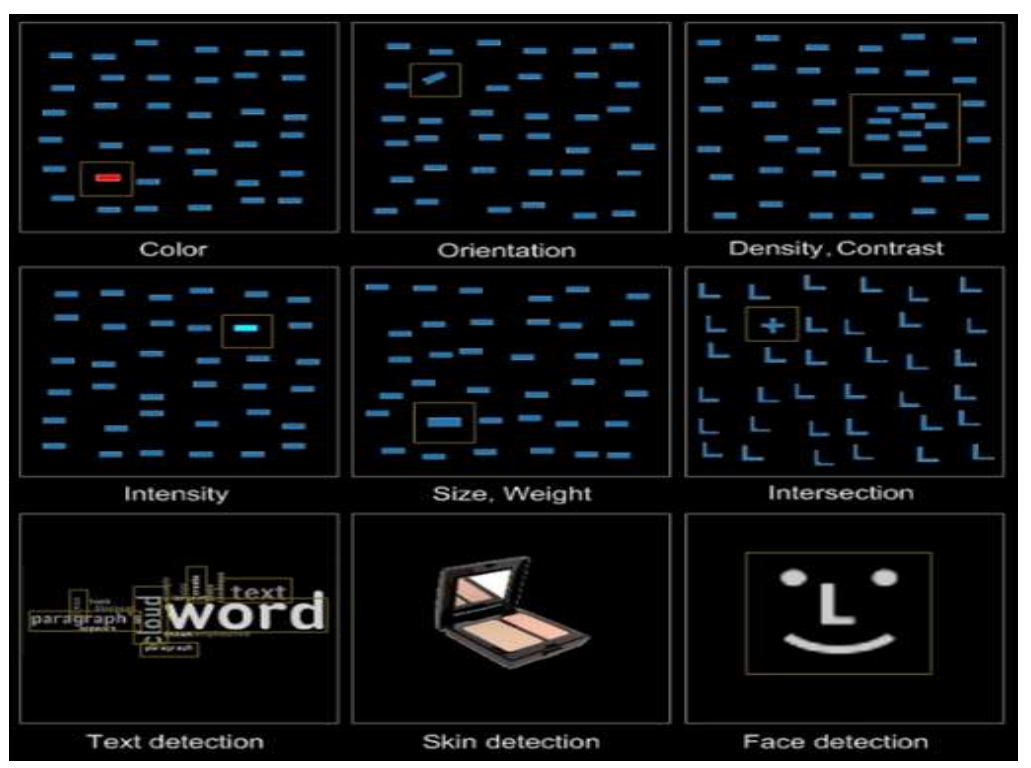

Gambar 3. Teknologi yang digunakan Feng-GUI 


\section{IMPLEMENTASI DAN ANALISIS DESAIN}

Selain teori "F", teori usability lain juga turut diaplikasikan untuk memperkuat analisis.
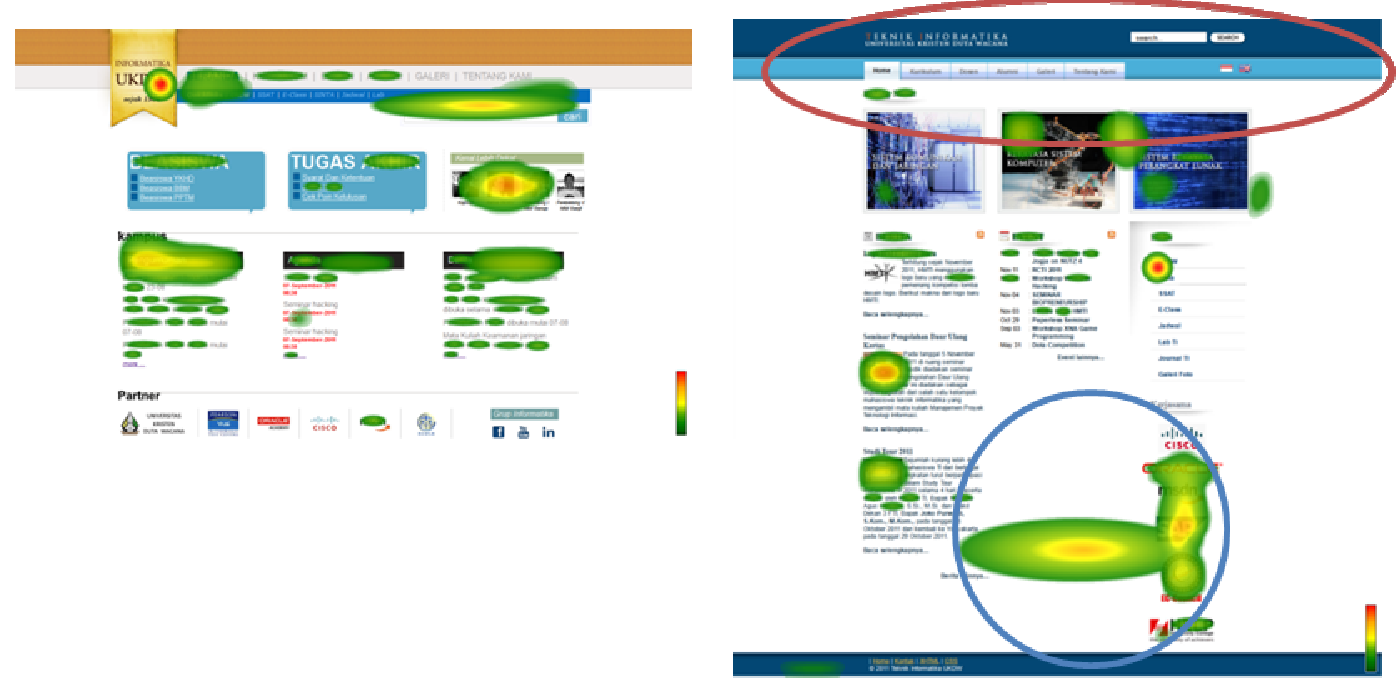

Gambar 4. Heatmap desain baru (kiri) dan lama (kanan)

Penempatan konten yang diletakkan pada area sekitar 250-350 pixel dari kiri halaman, dan beberapa konten penting diletakkan menurut kaidah pola bentuk $\mathrm{F}$ yang mana menyebutkan bahwa konten penting diletakkan pada sebelah kiri, dan atas. Hal ini sangat efektif meningkatkan atensi. Gambar 5 menunjukkan hasil pengujian menggunakan Feng-GUI. Hasil penerapan teori Krug terlihat bahwa Logo pada desain halaman Home mendapat atensi pertama kali.

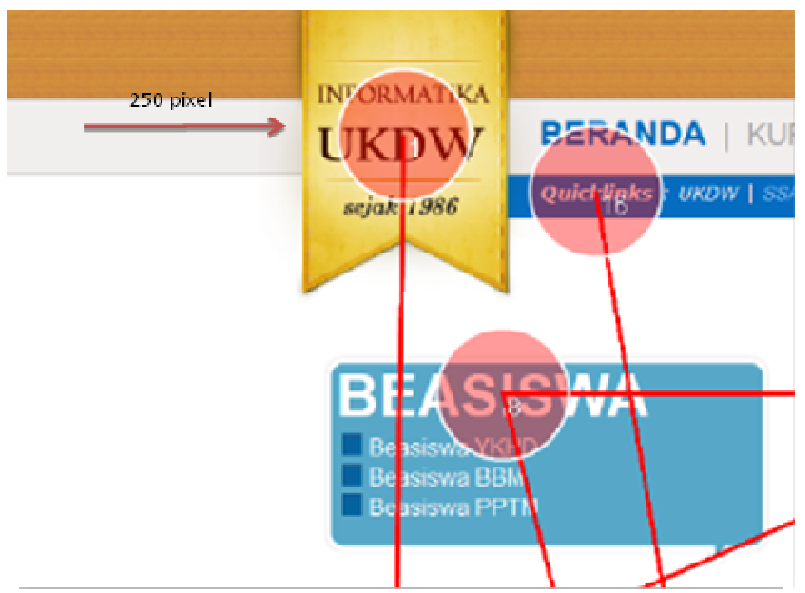

Gambar 5. Aplikasi teori Krug pada desain 
Desain baru juga mengaplikasikan salah satu teori Krug yang menyarankan agar menghindari teks yang tidak terlalu banyak dan gambar digunakan sewajarnya. Kolom berita juga diubah dari menampilkan gambar, judul dan isi berita, menjadi judul saja, dan jumlah yang dibatasi menjadi 4-5 judul berita saja. Sementara gambar dibatasi karena cenderung mencuri atensi lebih banyak.

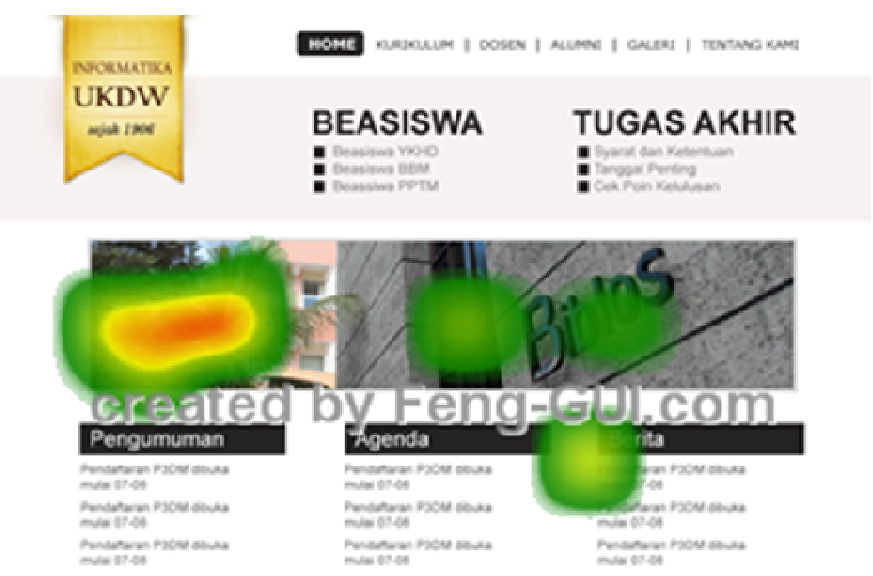

Gambar 6. Pengaruh gambar pada atensi

Penggunaan grid pada desain juga sangat membantu untuk menghasilkan desain dengan konten yang seimbang dan semakin memanfaatkan area kosong. Penggunaan gambar juga dikurangi dengan alasan mempengaruhi atensi ke elemen lain yang seharusnya penting untuk dilihat.

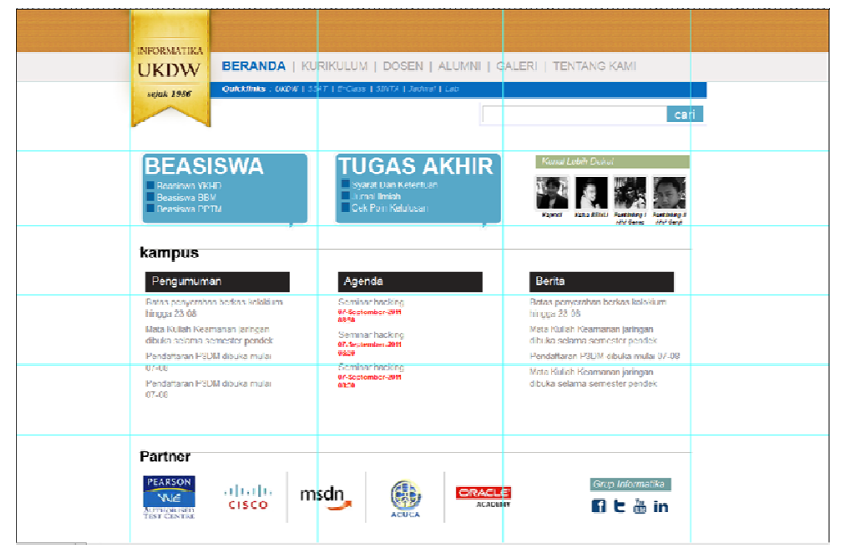

Gambar 7. Grid pada desain

Penggunaan latar belakang putih bertujuan untuk mengurangi visual noise (latar belakang yang mengganggu ) pada website yang dapat mengurangi atensi pada konten itu sendiri. Sehingga tiap elemen penting pada website dapat terlihat dengan jelas. 


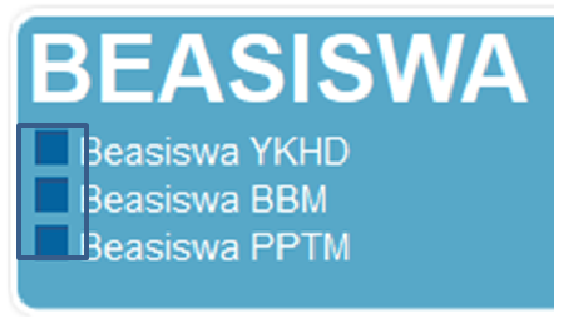

Gambar 8. Gestalt principle "Closure"

Bagian BEASISWA dan TUGAS AKHIR juga turut mengaplikasikan teori Gestalt yaitu closure, dimana elemen dibuat saling bersebelahan sehingga dianggap suatu kesatuan, perhatikan gambar dibawah ini
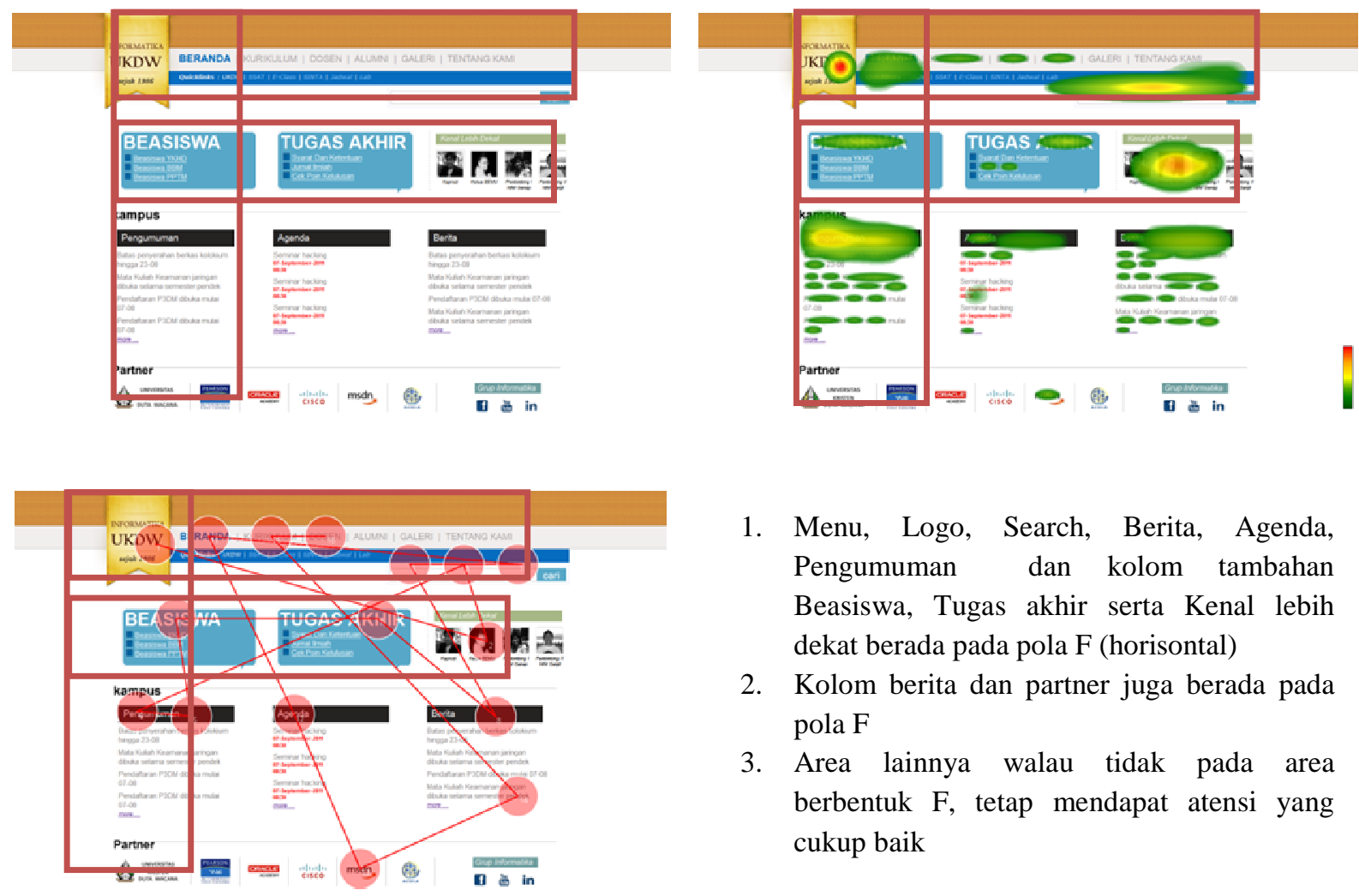

1. Menu, Logo, Search, Berita, Agenda, Pengumuman dan kolom tambahan Beasiswa, Tugas akhir serta Kenal lebih dekat berada pada pola $\mathrm{F}$ (horisontal)

2. Kolom berita dan partner juga berada pada pola $\mathrm{F}$

3. Area lainnya walau tidak pada area berbentuk F, tetap mendapat atensi yang cukup baik

Gambar 9. Pola F pada desain situs Prodi.Teknik Informatika yang baru

Untuk atensi, baik desain lama maupun baru sudah baik atensinya, yaitu berada pada bagian atas disekitar menu, dan Logo. Sementara untuk bagian gambar, atensi pada desain lama lebih baik. Hal ini dipengaruhi jenis gambar pada galeri itu sendiri. Atensi lebih banyak pada gambar wajah ketimbang bangunan (perhatikan tanda panah). 

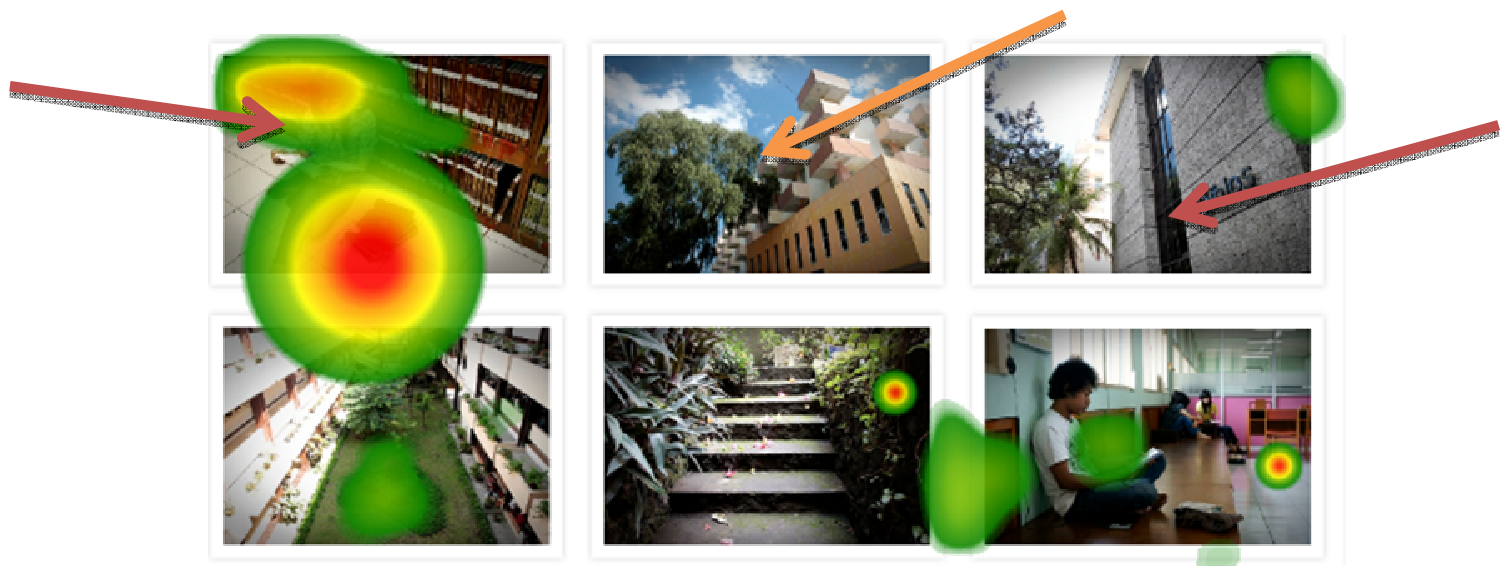

Gambar 10. Atensi pada objek wajah manusia (garis merah)

Salah satu implementasinya dapat dilihat pada desain baru halaman dosen pada gambar 11 berikut:
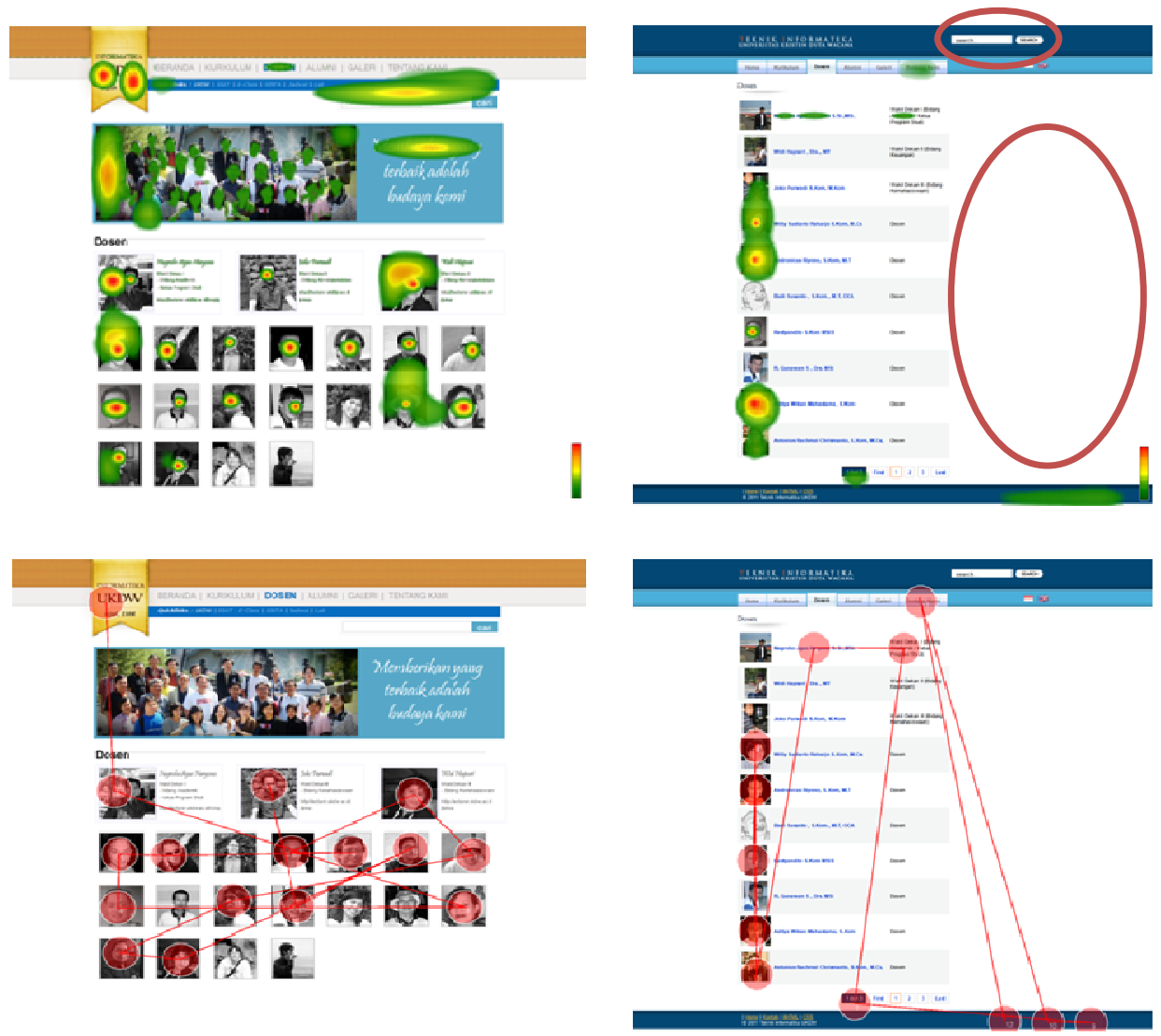

Gambar 11. Perbandingan heatmap antara desain baru dan desain lama

Beberapa Perbaikan pada website baru antara lain, tingkat atensi yang lebih baik dan minim scrolling. Desain baru mengelompokkan dosen dengan pola GRID, sementara untuk dosen dengan jabatan tertentu dibuat lebih besar dengan tujuan untuk menunjukkan adanya perbedaan antara kelompok dosen yang satu dengan yang lain perbedaan dan meningkatkan 
atensi. Keterangan mengenai dosen dibatasi Cuma sebatas nama dan konsentrasi, dengan alasan dosen sudah punya halaman lecturer sendiri. Dan informasi berupa nama dan konsentrasi pengajaran juga merupakan hal penting bagi mahasiswa, terutama untuk menentukan dosen pembimbing KP dan TA. Efek berupa tooltip akan muncul dari bawah apabila gambar disorot
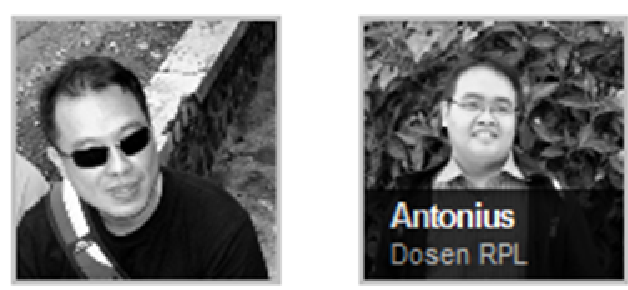

Gambar 12. Efek dosen ketika disorot

Desain final halaman Kurikulum dari website Prodi. Teknik Informatika dapat dilihat pada gambar 13 berikut:
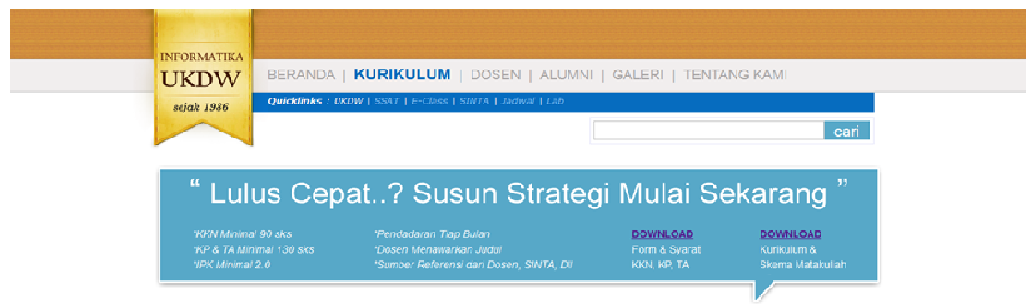

Kurikulum
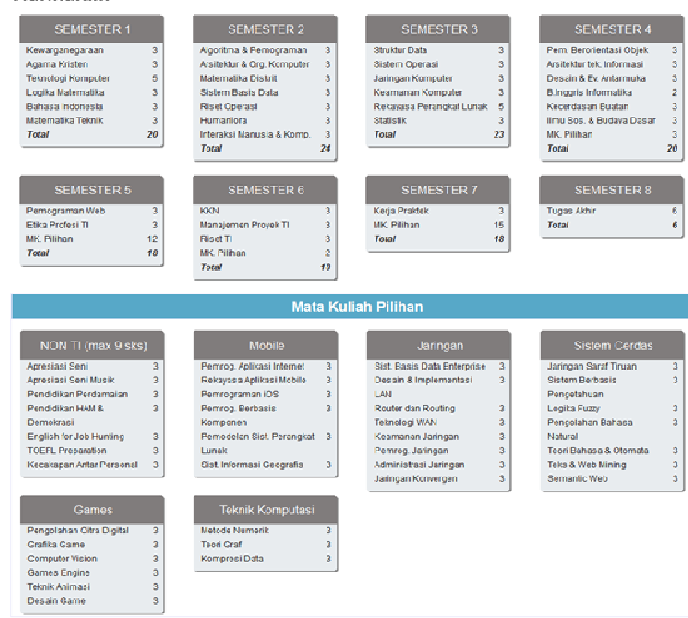

Gambar 11. Desain baru halaman kurikulum

Desain yang baru lebih optimal dalam memanfaatkan area dimana penyebaran atensi lebih merata. Perbaikan desain dilakukan dengan memperjelas pembagian area (Logo, Menu, Judul, Subjudul) dan mengurangi banyaknya teks yang ukurannya hampir sama tanpa ada perlakuan khusus pada hal tertentu yang memang ingin ditonjolkan. 


\section{PENGUJIAN AKHIR DESAIN}

Untuk memperkuat hasil penelitian, desain kembali diujikan kepada pengguna sebanyak 7 orang dengan umur dan program studi berbeda untuk mengetahui tingkat atensi terutama di area berbentuk F. Partisipan diminta melakukan task sederhana, yang diawali dengan melatih partisipan dengan halaman website berbeda sebelum dilakukan pengujian ke desain sebenarnya

Halaman website dibagi menjadi 4 area untuk dan user diminta untuk melihat dan mengingat arah pergerakan mata, hal ini penting agar kemungkinan kesalahan dan tingkat keberhasilan terhadap desain semakin dapat dipercaya.

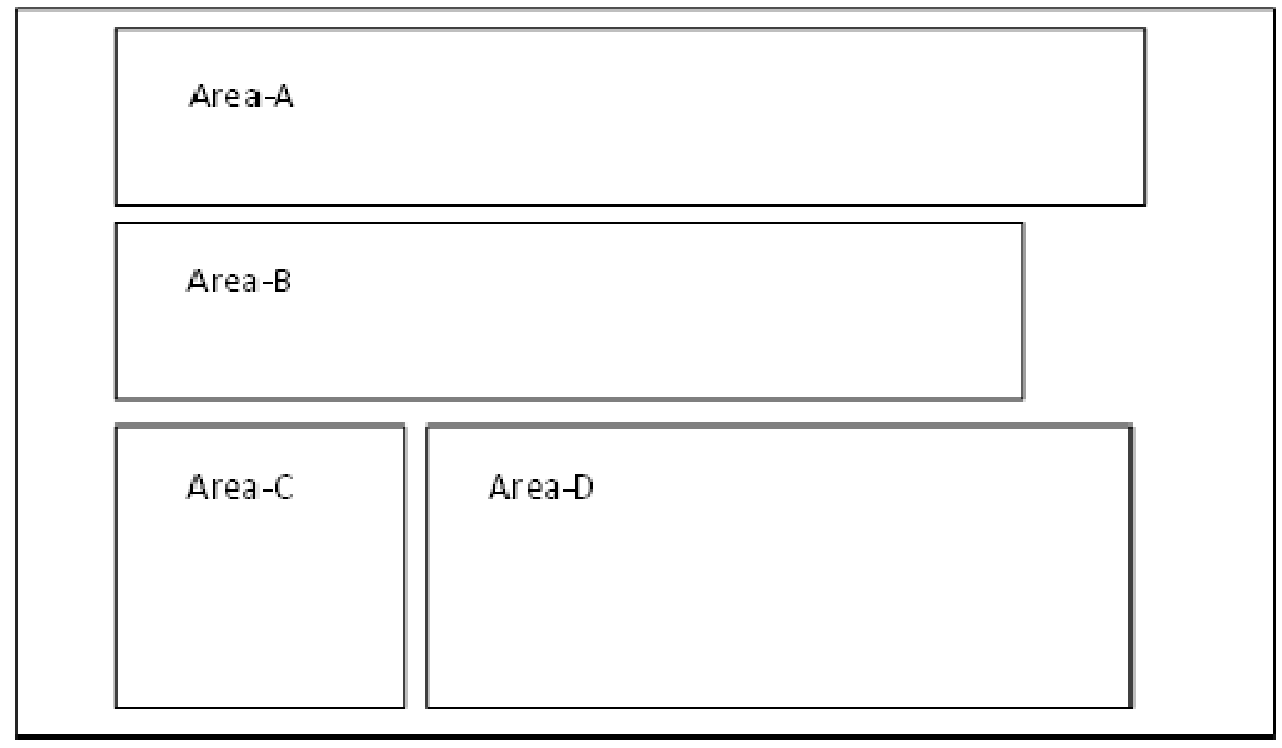

Gambar 12. Pembagian Area pengujian

Beberapa temuan dari hasil pengujian akhir di atas ialah, diketahui bahwa atensi sangat baik pada area-a dan area-b, apalagi jika diperkuat dengan warna dan penggunaan ukuran karakter/teks yang cukup jelas, jelas teori F-pattern sangat berpengaruh pada hasil ini.

Dari data yang diperoleh didapat temuan bahwa user (terutama yang baru pertama kali melihat desain) cenderung melihat ke bagian atas (LOGO) yaitu di area-a, selanjutnya untuk halaman lain (kedua dan seterusnya) lebih mengarah ke area-b, hal ini kemungkinan dipengaruhi oleh desain pada area-a yang sama di tiap halaman (Logo, Menu, Search berada di area yang sama), hal ini sangat erat hubungannya dengan hasil temuan George Buscher yang mana menyatakan bahwa salience pada fixasi kedua lebih dipengaruhi oleh memory dan ekspektasi user. 


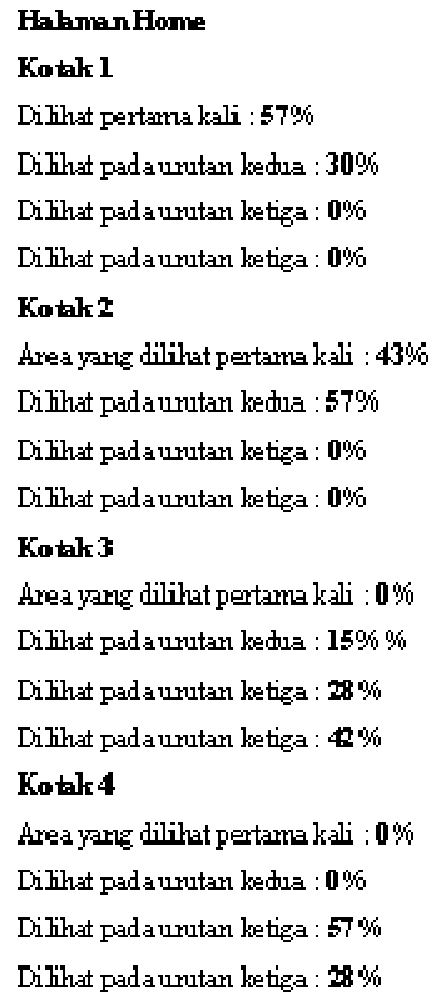

\section{Halaman Ahmni \\ Kotak1 \\ Dilihat Fertama kali : $\mathbf{4 0 \%}$ \\ Dilhat padauntan kedna: 30\% \\ Dilihat Fadauntan ketiga : $15 \%$ \\ Dilihat pada nontan ketiza : $15 \%$ \\ Kotak?}

Area yane dilihat fertama kali : $5 \%$

Dilihat padauntar kedua : $40 \%$

Dilihat Fadauntan ketiga : $0 \%$

Dilihat padanntan ketiza : $0 \%$

\section{Kotal:3}

Area yane dilihat portama kali : $0 \%$

Dilihat Fad a untan kedua : $53 \% \%$

Dilihat Fadauntan ketiga : $47 \%$

Dilihat padanotan ketiza : $0 \%$

Kohk4

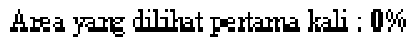

Dilihat Fadauntan kedna: $0 \%$

Dilihat pasanntan ketiza : $15 \%$

Dilihat padanntan ketiza : $57 \%$

Gambar 13. Hasil pengujian

Dari data tersebut terbukti bahwa area 1 dan 2 merupakan area dengan tingkat kemungkinan mendapat atensi paling baik dibanding area 3 dan 4, dan teruji bahwa pola membaa F-Shape pattern sangat efektif untuk penempatan informasi yang penting

Desain situs yang dibuat juga diujikan pada beberapa browser yang banyak digunakan, hasilnya tampak bahwa desain, konten dan efek dapat berjalan dengan baik, seperti tampak pada gambar 14 dan 15 berikut ini:
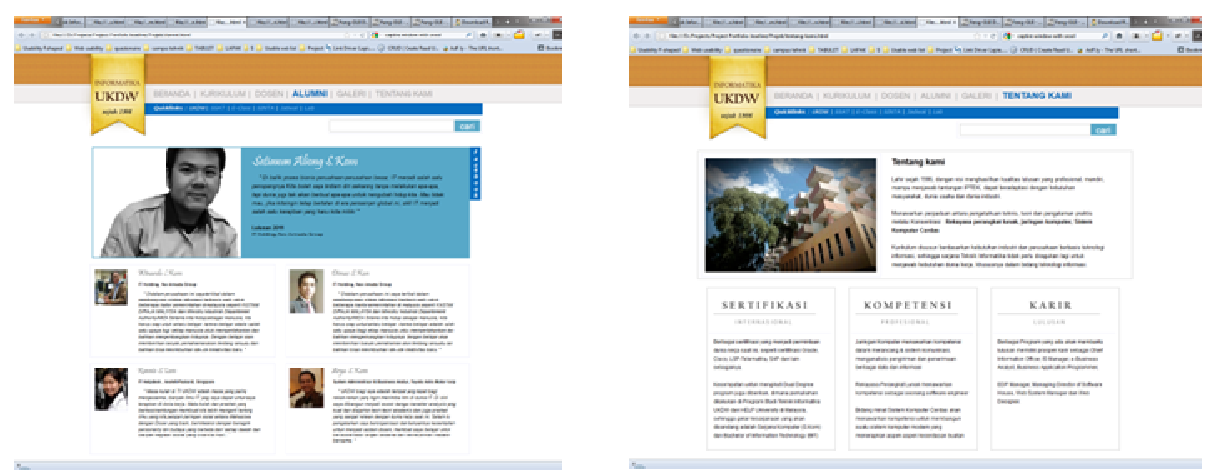

Gambar 14. Pengujian pada browser Firefox 

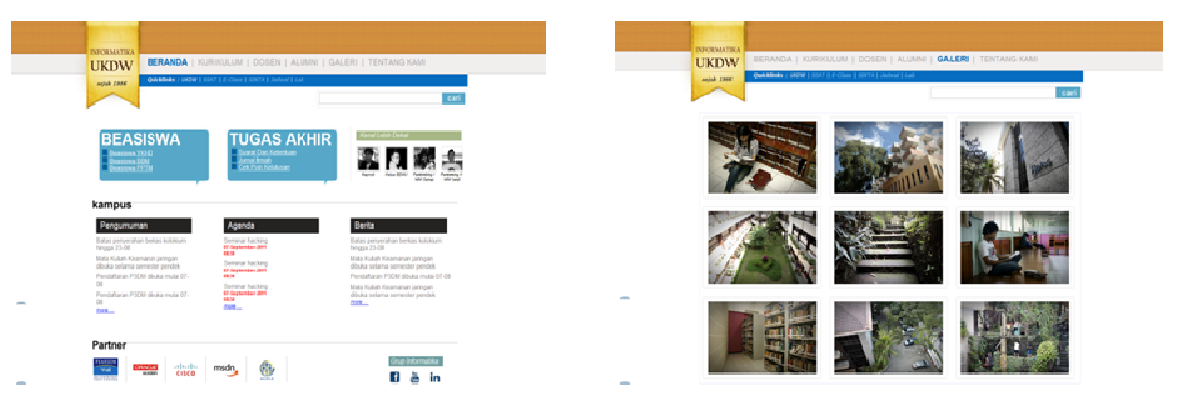

Gambar 15. Pengujian pada browser Google Chrome

Selain kedua browser di atas, pengujian juga dilakukan pada browser Internet Explorer, Opera, dan Apple Safari.

\section{KESIMPULAN}

a) Dari hasil pengujian desain akhir ke responden, dibuktikan bahwa area dua garis horizontal pada pola bentuk "F" merupakan area yang pertama kali dilihat dan paling banyak m(masing-masing 50\% dan 57\% dari total partisipan), sementara untuk garis vertikal setelah kedua garis sejajar merupakan area yang dilihat pertama kali paling sedikit (29\% dari total partisipan)

b) Pola bentuk "F" (F-Shape pattern) memang berperan penting pada rancangan konten website, karena berdasarkan aspek psikologi, manusia cenderung melakukan scanning pada website bukan membacanya secara keseluruhan, dan dengan kebiasaannya membaca mulai dari area sebelah kiri atas, konten penting juga sebaiknya diletakkan pada area tersebut. Hal ini dibuktikan dengan pengujian akhir terhadap responden.

c) Dari Hasil Kuisoner, Beberapa konten penting yang diharapkan ditampilkan pada wesite berupa : Info Beasiswa, Info TA dan KP, Info Lowongan, dan Link Ke situs Jejaring social seperti Facebook

d) Teks dengan blok yang terlalu besar (terlalu banyak dan panjang kebawah) juga dapat menurunkan tingkat atensi, apalagi jika tidak ada perbedaan jelas antara Judul Subjudul dan kalimat.

e) Berdasarkan hasil Pengujian menggunakan Feng-GUI, Gambar cenderung menyedot atensi berlebih dibanding teks, apalagi gambar dengan objek wajah dan manusia

f) Grid efektif menjadikan halaman website terlihat terstruktur, dan pemanfaatan area kosong menjadi lebih baik. 
g) Panjangnya halaman (web page) sangat berpengaruh terhadap kenyamanan user dan pola scanning user terhadap website. atensi cenderung terjadi pada area kiri saja apabila halaman begitu panjang. Bahkan dapat mengurangi atensi di area F.

\section{Daftar Pustaka}

Could I have the Menu Please? An Eye Tracking Study of Design Conventions, (2004) dalam http://www.cs.ucl.ac.uk/research/higherview/mccarthy_menu.pdf; 26 januari 2011

___, F-Shaped Pattern For Reading Web Content, (2006) dalam http://www.useit.com/alertbox/reading_pattern.html; 17 April 2006

Horizontal Attention leans left, (2010) dalam http://www.useit.com/alertbox/horizontal-attention.html; 6 April 2010

___ Human-Computer Interaction: Principles of Interface Design (2004) dalam http://www.vhml.org/theses/nannip/HCI_final.htm; 20 januari 2011

___ Scrolling and Attention, (2010) dalam http://www.useit.com/alertbox/scrolling-attention.html; 22 Maret 2010

, What Do You See When You're Surfing ? Using Eyetracking to Predict Salient Regios of Web Pages, (2009) dalam http://cs.utsa.edu/ jpq/Site/teaching/uiu-f11/6.pdf; 6 April 2009

Ambler, \& Scott, W. (2000, Oktober 26). User Interface Design : Tips and tehniques. http://www.ambysoft.com/userInterfaceDesign.pdf.

Krug, S. (2006). Don't Make Me Think $2^{\text {nd }}$ edition. New Riders

Nielsen, J., \& Pernice, K. (2009). Eyetracking Web Usability. New Riders.

Tullis, T., \& Albert, B (2008). Measuring The user Experience. Morgan Kaufman Publishers 